\title{
Plantas de Cobertura no Controle de Plantas Daninhas na Cultura do Tomate em Plantio Direto ${ }^{1}$
}

\author{
Cover Crops Used to Control Weeds Under the No-Tillage Tomato Production System
}

\author{
SILVA HIRATA, A.C. ${ }^{2}$, HIRATA, E.K. ${ }^{3}$, MONQUERO, P.A. ${ }^{4}$, GOLLA, A.R. ${ }^{5}$ e NARITA, N. ${ }^{5}$
}

\begin{abstract}
RESUMO - O plantio direto do tomateiro é um sistema que busca maior sustentabilidade, porém são escassas as informações sobre o manejo de plantas daninhas nessa nova modalidade de cultivo. O objetivo deste trabalho foi avaliar cinco tipos de cobertura do solo (Brachiaria decumbens, B. ruziziensis, Pennisetum glaucum, comunidade infestante e tratamento sem cobertura vegetal) para plantio direto do tomateiro rasteiro, conduzido no sistema meia estaca, em complementação ao controle químico com herbicidas. P. glaucum foi a espécie que proporcionou maior cobertura do solo até a colheita do tomate; todavia, a taxa de decomposição da palha foi maior que a das demais coberturas. As coberturas de solo compostas pelas gramineas forrageiras $B$. decumbens, $B$. ruziziensis e Pennisetum glaucum reduziram a densidade e a massa seca das plantas daninhas. O uso da comunidade infestante para obtenção de palha promoveu reduzida cobertura do solo e elevada emergência de plantas daninhas, semelhantes às do solo sem cobertura. $B$. decumbens apresentou rebrota durante o ciclo do tomateiro, o que não ocorreu com B. ruziziensis.
\end{abstract}

Palavras-chave: tomate rasteiro, supressão de plantas daninhas, plantio direto, palha.

\begin{abstract}
Tomato no tillage system is a more sustainable system. However, information about weed management in this new cultivation modality is scarce. The objective of this work was to evaluate five vegetation covers (Brachiaria decumbens, B. ruziziensis, Pennisetum glaucum, community weed and the treatment without vegetable covering) for no tillage system of the staked processing tomato crop combined with weed chemical control. P. glaucum provided the most soil cover to the tomato crop, although straw decomposition rate was higher than those of the other covers. The soil cover by the forage grasses B. decumbens, B. ruziziensis and Pennisetum glaucum reduced the density and dry mass of the weeds. The use of the community weeds for straw obtaining promoted reduced covering of the soil and larger emergency of weeds, similar to the treatment without vegetable covering. B. decumbens presented resprouting capacity during the cycle of the tomato that didn't happen with $\boldsymbol{B}$. ruziziensis.
\end{abstract}

Keywords: tomato, weeds suppression, no till, straw.

\section{INTRODUÇÃO}

Em culturas hortícolas, as práticas culturais envolvem grande distúrbio no solo, como aração, gradagem, enxada rotativa e baixo nivel de estresse com uso de adubações química e orgânica, irrigações frequentes e abundantes, facilitando a ocorrência de elevadas populações de plantas daninhas na área (Pitelli, 1984; Pereira, 1987).

A composição e as densidades populacionais das comunidades infestantes são influenciadas pelos sistemas de produção de

Recebido para publicação em 9.10.2008 e na forma revisada em 21.8.2009.

D.Sc., Pesquisadora científica da Agência Paulista de Tecnologia dos Agronegócios -APTA, Caixa Postal 298, 19015-970 Presidente Prudente-SP, <andreiacs@apta.sp.gov.br>; ${ }^{3}$ Engo-Agr $^{0}$, Viveiro NH, 19160-000, Álvares Machado-SP, ${ }^{4}$ D.Sc., Prof. Adjunto, Universidade Federal de São Carlos - UFSCAR, Caixa Postal 153, 13600-970 Araras-SP, 5 Pesquisadores da APTA. 
cobertura morta (Correia et al., 2006). A interferência exercida pelas plantas daninhas na cultura do tomate altera o crescimento e o desenvolvimento, reduzindo o tamanho, o peso e o número de frutos (Qasem, 1992). Têm sido verificadas perdas de até $75 \%$ da produção do tomateiro rasteiro, ocasionadas por plantas daninhas (Nascente et al., 2004).

Os programas de agricultura sustentável para a tomaticultura industrial constituem atualmente o centro das atenções das empresas processadoras em operação (Melo \& Vilela, 2005). Nesse contexto, o sistema de plantio direto tem-se mostrado muito mais que um método de conservação do solo e vem contribuindo para a sustentabilidade da agricultura, mantendo alta produção, sem danificar o solo e o meio ambiente (Amaral, 2001). Na região do Cerrado, o sistema de plantio direto vem sendo adotado em razão dos benefícios que oferece. Todavia, em consequência da escassez de pesquisas específicas sobre tomateiro para processamento, as práticas de cultivo utilizadas são, em geral, as mesmas recomendadas para o sistema de plantio convencional (Marouelli et al., 2006).

A cobertura do solo apresenta efeito físico, químico e biológico na supressão de plantas daninhas na cultura do tomate. Embora dependendo de fatores como local e pressão de plantas daninhas, a palha pode até eliminar a necessidade de aplicação de herbicidas (Smeda \& Weller, 1996). Algumas espécies de plantas de cobertura têm apresentado excelentes resultados na produção de palha para plantio direto, como o milheto (Correia et al., 2006; Suzuki \& Alves, 2006; Timossi et al., 2007; Bôer et al., 2008) e as braquiárias (Timossi et al., 2007; Correia et al., 2006).

Produtores têm relatado benefícios da palha, como a redução das perdas por podridões e a manutenção do plantio na mesma área por um período maior de tempo (mais ciclos anuais), o que é de grande importância, visto a dificuldade em encontrar novas áreas para arrendamento e cultivo do tomateiro, devido principalmente à expansão da cana-de-açúcar.

Desse modo, o estudo da persistência da palha proveniente de diferentes plantas de cobertura, assim como o impacto dessa tecnologia no controle de plantas daninhas, é de grande relevância nesse novo padrão de cultivo da cultura do tomate.

O objetivo deste trabalho foi avaliar culturas de cobertura do solo na cultura do tomate rasteiro, conduzido no sistema meia estaca, como ferramenta adicional ao controle químico de plantas daninhas.

\section{MATERIAL E MÉTODOS}

O ensaio foi realizado a campo, no município de Álvares Machado-SP, em solo classificado como Argissolo VermelhoAmarelo textura arenosa, cujas principais características químicas são: $\mathrm{pH}$ em $\mathrm{CaCl}_{2}$ de 6,2; matéria orgânica de $8 \mathrm{~g} \mathrm{dm}^{-3}$; V de $70 \%$; teores de $\mathrm{P}, \mathrm{K}, \mathrm{Zn}, \mathrm{Fe}, \mathrm{Mn}, \mathrm{Cu}$ e $\mathrm{B}$ de 200,0; 4,$3 ; 6,0 ; 35,5 ; 16,6 ; 19,1 ;$ e $0,13 \mathrm{mg} \mathrm{dm}^{-3}$ e de $\mathrm{Ca}, \mathrm{Mg}, \mathrm{H}+\mathrm{Al}$ de 26,0; 7,0; e 16,0 $\mathrm{mmol}_{\mathrm{c}} \mathrm{dm}^{-3}$.

Foram avaliados cinco tipos de cobertura do solo (palha de Brachiaria decumbens, B. ruziziensis, milheto (Pennisetum glaucum), comunidade infestante e tratamento sem cobertura vegetal) na cultura do tomate rasteiro, híbrido Vênus, conduzido no sistema meia estaca e irrigado por gotejamento. Os tratamentos foram dispostos no delineamento em blocos ao acaso, com cinco repetições. As forrageiras $B$. decumbens, B. ruziziensis e milheto foram semeadas em parcelas de $6,0 \times 7,5 \mathrm{~m}$, em 9/10/2006, nas densidades de 25, 25 e $30 \mathrm{~kg} \mathrm{ha}^{-1}$, respectivamente.

As espécies forrageiras, assim como a comunidade infestante emergida a partir da semeadura das forrageiras, foram dessecadas aos 92 dias após a semeadura, com 2,88 $\mathrm{kg} \mathrm{ha}^{-1}$ de glyphosate. A dessecação foi realizada uma semana antes do transplantio das mudas do tomateiro, as quais foram plantadas no espaçamento de $1,5 \times 0,60 \mathrm{~m}$, utilizando um sulcador com disco de corte para cortar a palha na linha de plantio, adubando-se em seguida com semeadora de plantio convencional com 1,95 tha-1 da formulação 04-24-12. A adubação de cobertura foi feita com $0,4 \mathrm{tha}^{-1}$ da fórmula 12-00-12, aos 45 dias após o transplante.

Cada parcela foi composta por cinco linhas da cultura, com seis metros de comprimento. O controle químico de plantas daninhas foi o usualmente feito pelos produtores, com duas aplicações de metribuzin, cada uma utilizando 
$0,24 \mathrm{~g} \mathrm{ha}^{-1}$, aos 11 e 51 dias após o transplante, e duas aplicações de fluazifop-p-butil (150 e $200 \mathrm{~g} \mathrm{ha}^{-1}$ ), aos 15 e 44 dias após o transplante.

A palha resultante da dessecação das espécies forrageiras e das plantas infestantes foi avaliada aos 0, 46, 85 e 136 dias da dessecação, com auxílio de um quadro de $0,25 \mathrm{~m}^{2}$, lançado duas vezes em cada parcela. As plantas daninhas foram amostradas (identificadas, quantificadas e determinada a massa seca) na entrelinha da cultura por ocasião da avaliação da palha; na última avaliação (final da colheita do tomateiro), foi avaliada também nas linhas de plantio. Para obtenção da massa seca da palha e das plantas daninhas, o material coletado foi seco em estufa de circulação forçada de ar. Os dados resultantes da amostragem da palha, massa seca total e densidade de plantas infestantes foram submetidos à análise de variância. Para os dados de palha, foram ajustados modelos de regressão, escolhidos considerando-se a significância dos coeficientes de regressão, utilizando-se o teste t a $5 \%$ de probabilidade, o coeficiente de determinação e o significado biológico. As médias de massa seca e densidade de plantas daninhas foram comparadas pelo teste de Tukey a 5\% de probabilidade.

\section{RESULTADOS E DISCUSSÃO}

Houve interação significativa entre as épocas de avaliação e os tipos de cobertura do solo, indicando que a persistência da palha dos materiais avaliados foi distinta na cultura do tomate, como pode ser visualizado na Figura 1.

$\mathrm{O}$ milheto forneceu maior quantidade de palha para o sistema $\left(21 \mathrm{t} \mathrm{ha}^{-1}\right)$, porém apresentou taxa de decomposição superior à das braquiárias (Tabela 1), o que também foi constatado por Timossi et al. (2007). Brachiaria decumbens proporcionou aproximadamente 59 e $80 \%$ da palha obtida pelo milheto por ocasião da dessecação das espécies e da colheita do tomate, respectivamente, o que evidencia a maior persistência da braquiária. $B$. decumbens manteve quantidade de palha ligeiramente superior à de $B$. ruziziensis até a colheita, com taxa de decomposição semelhante entre essas espécies. A dessecação da comunidade infestante, composta principalmente por capim-colchão (Digitaria horizontalis) e capim-pé-de-galinha (Eleusine indica), não apresentou cobertura satisfatória do solo, representando aproximadamente $36 \%$ da palha proporcionada por $B$. decumbens na colheita do tomate; contudo, a taxa de

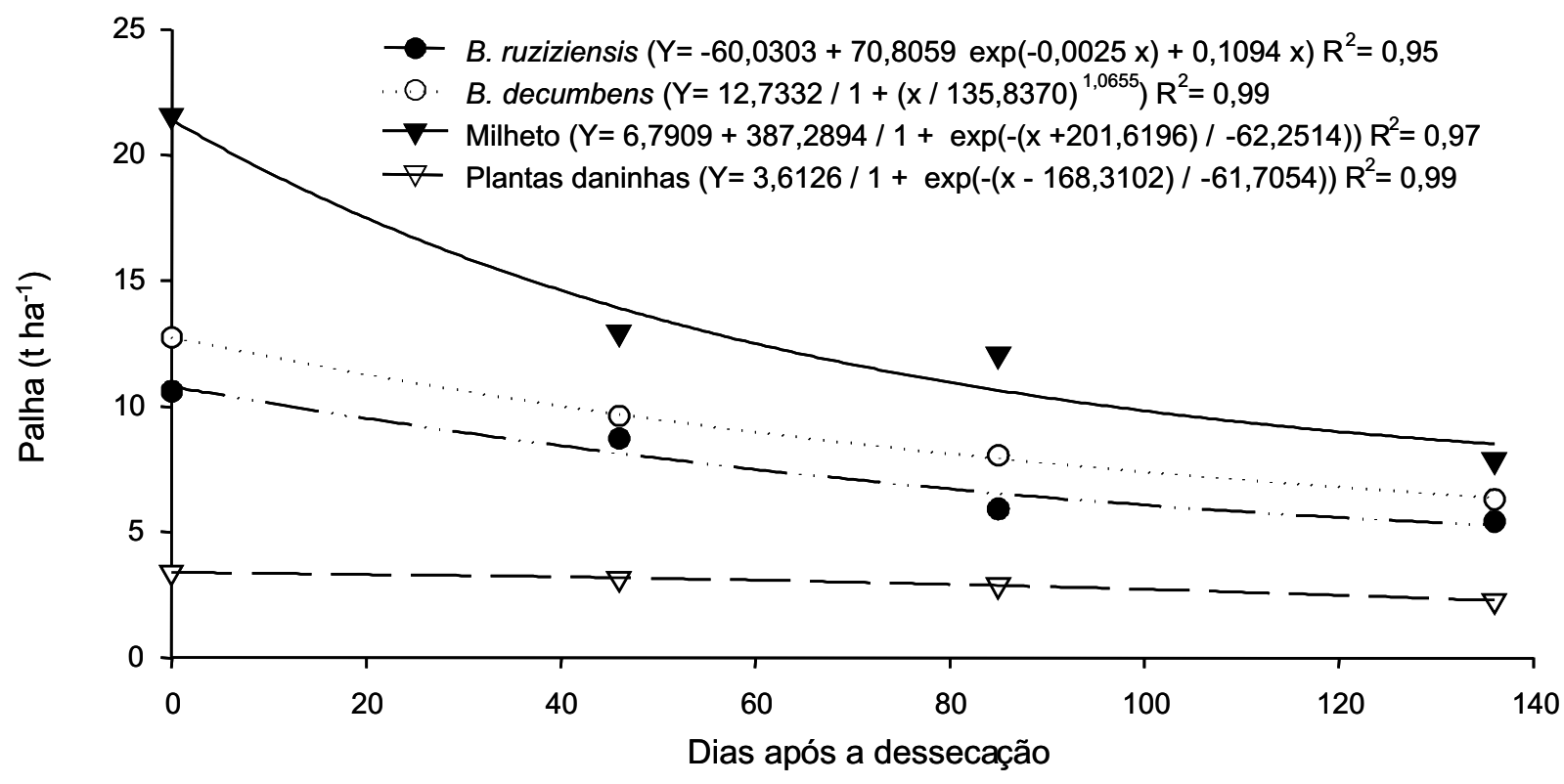

Figura 1 - Persistência da palha de plantas de cobertura do solo na cultura do tomate rasteiro conduzido no sistema meia estaca. 
decomposição foi baixa. Esses dados corroboram os de Meschede et al. (2007), os quais verificaram que a vegetação espontânea apresentou baixos valores de biomassa para cobertura do solo.

Na Figura 2 podem ser visualizados os dados de temperatura e precipitação pluvial no decorrer do ensaio, observando-se precipitação regular, com maior intensidade em dezembro e janeiro, que, aliado à temperatura máxima superior a $30{ }^{\circ} \mathrm{C}$, favoreceram a decomposição da cobertura do solo.

Os dados de número e massa seca das plantas daninhas emergidas nos diferentes

Tabela 1 - Número e massa seca de plantas daninhas emergidas sobre a palha de gramíneas forrageiras na cultura de tomateiro rasteiro conduzido no sistema meia estaca, aos 46 dias após a dessecação, na entrelinha da cultura

\begin{tabular}{|c|c|c|c|c|c|c|c|c|c|c|}
\hline \multirow[b]{2}{*}{ Espécie (plantas $\mathrm{m}^{-2}$ ) } & \multicolumn{10}{|c|}{ Cobertura do solo } \\
\hline & \multicolumn{2}{|c|}{$\begin{array}{l}\text { Brachiaria } \\
\text { decumbens }\end{array}$} & \multicolumn{2}{|c|}{$\begin{array}{l}\text { Brachiaria } \\
\text { ruziziensis }\end{array}$} & \multicolumn{2}{|c|}{$\begin{array}{l}\text { Pennisetum } \\
\text { glaucum }\end{array}$} & \multicolumn{2}{|c|}{ Plantas Daninhas } & \multicolumn{2}{|c|}{ Sem cobertura } \\
\hline Digitaria horizontalis & \multicolumn{2}{|c|}{$\overline{0}$} & \multicolumn{2}{|c|}{21} & \multicolumn{2}{|c|}{0} & \multicolumn{2}{|c|}{1.071} & \multicolumn{2}{|c|}{848} \\
\hline Amaranthus sp. & \multicolumn{2}{|c|}{0} & \multicolumn{2}{|c|}{1} & \multicolumn{2}{|c|}{1} & \multicolumn{2}{|c|}{0} & \multicolumn{2}{|c|}{2} \\
\hline Commelina benghalensis & \multicolumn{2}{|c|}{0} & \multicolumn{2}{|c|}{1} & \multicolumn{2}{|c|}{1} & \multicolumn{2}{|c|}{0} & \multicolumn{2}{|c|}{0} \\
\hline Pennisetum glaucum & \multicolumn{2}{|c|}{0} & & & \multicolumn{2}{|c|}{68} & \multicolumn{2}{|c|}{0} & \multicolumn{2}{|c|}{1} \\
\hline Eleusine indica & \multicolumn{2}{|c|}{2} & & & \multicolumn{2}{|c|}{0} & \multicolumn{2}{|c|}{114} & \multicolumn{2}{|c|}{27} \\
\hline Portulaca oleracea & \multicolumn{2}{|c|}{0} & & & \multicolumn{2}{|c|}{1} & \multicolumn{2}{|c|}{24} & \multicolumn{2}{|c|}{26} \\
\hline Euphorbia heterophylla & \multicolumn{2}{|c|}{0} & & & \multicolumn{2}{|c|}{0} & \multicolumn{2}{|c|}{1} & & 0 \\
\hline Richardia brasiliensis & & & & & & & & 2 & & 0 \\
\hline Rebrota $B$. decumbens & & & & & & & & 0 & & 0 \\
\hline Macsa soco $\left(\mathrm{m}^{-2}\right)$ & $\mathrm{M}$ & $\mathrm{D}$ & $\mathrm{M}$ & $\mathrm{D}$ & $\bar{M}$ & $\mathrm{D}$ & $\mathrm{M}$ & $\mathrm{D}$ & $\bar{M}$ & $\mathrm{D}$ \\
\hline & 0,96 & 0,00 & 0,17 & 0,12 & 3,23 & 0,03 & 12,0 & 1,39 & 16,0 & 0,83 \\
\hline
\end{tabular}

$\mathrm{M}=$ monocotiledôneas; $\mathrm{D}=$ dicotiledôneas.

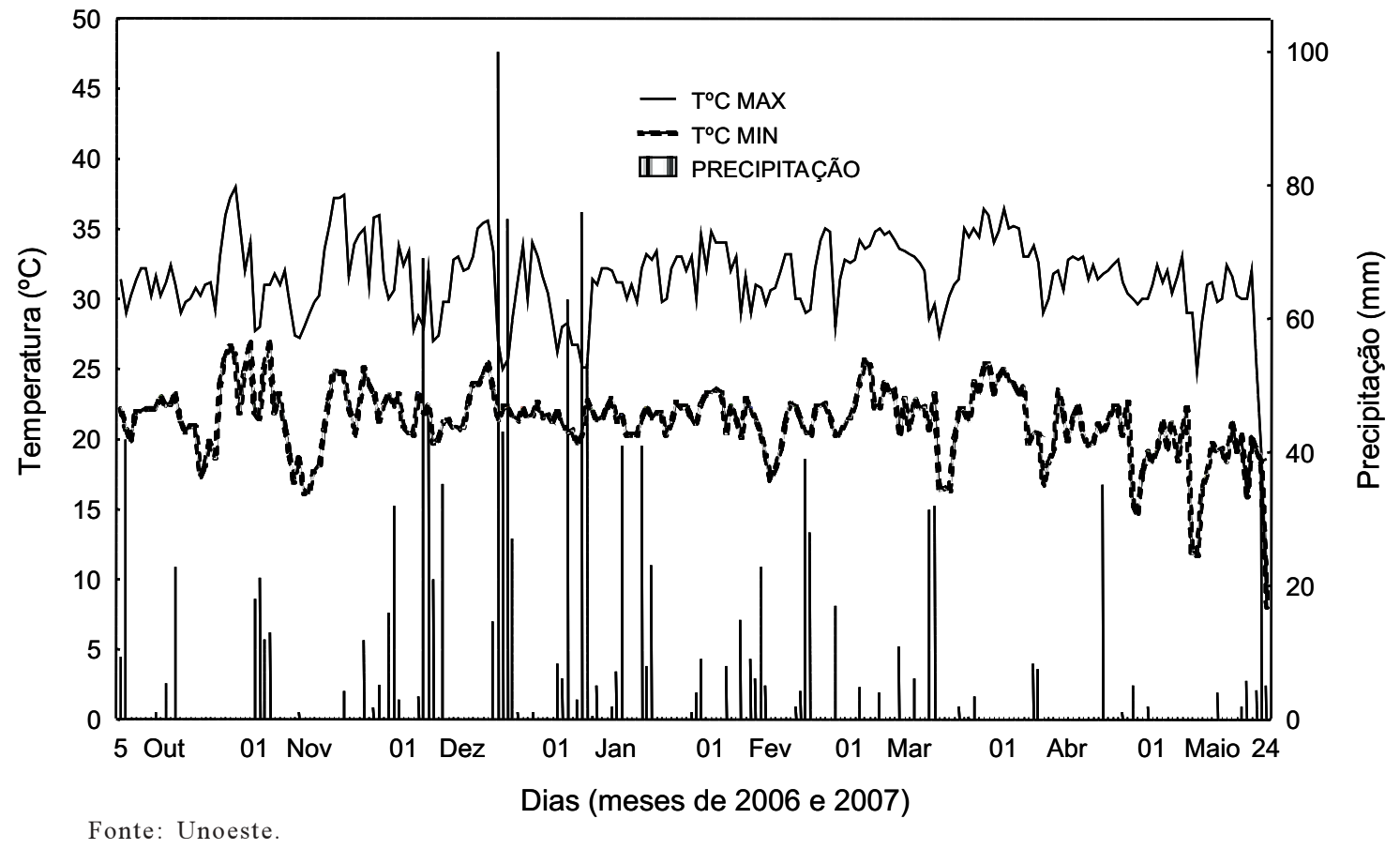

Figura 2 - Dados de precipitação pluvial, temperatura máxima e mínima durante a realização do ensaio. 
manejos de cobertura do solo estão apresentados na Tabela 1. Na avaliação feita aos 46 dias após a dessecação (DAD), ou seja, aos 28 e 24 dias após a primeira aplicação do metribuzin e fluazifop-p-butil, respectivamente, observou-se excelente controle das plantas infestantes dicotiledôneas, embora a área apresentasse elevado banco de sementes de beldroega (Portulaca oleracea) e trapoeraba (Commelina benghalensis). Todavia, verificouse elevada emergência de espécies gramíneas, uma vez que o graminicida é absorvido pelas folhas e apresenta baixa persistência no solo (Rodrigues \& Almeida, 2005), não exercendo efeito sobre as sementes que germinaram e as plântulas que emergiram após a aplicação. Já o metribuzin apresenta controle em pós-emergência e maior persistência no solo (Rodrigues \& Almeida, 2005), exercendo maior controle das dicotiledôneas.

A palha das espécies forrageiras reduziu a densidade e massa seca das espécies infestantes, especialmente as gramineas. Trabalhos realizados por Trezzi \& Vidal (2004) mostram que a presença de $4 \mathrm{tha}^{-1}$ de palha de sorgo ou milheto na superfície do solo reduziu a população de Sida rhombifolia em até $93 \%$. Neste ensaio, os tratamentos com cobertura pela comunidade infestante e sem cobertura do solo apresentaram alta infestação de gramineas, sobretudo $D$. horizontalis e E. indica, evidenciando a importância do manejo de coberturas do solo para complementar o controle químico na cultura do tomate. Meschede et al. (2007), comparando plantas de cobertura na supressão de plantas infestantes, também verificaram maior infestação de plantas daninhas quando foi utilizada vegetação espontânea como cobertura do solo.

Aos 27 e 34 dias após a segunda aplicação do metribuzin e fluazifop-p-butil, respectivamente, foi realizada a segunda avaliação das plantas daninhas. A comunidade infestante representada pelas espécies dicotiledôneas continuou com excelente controle, com redução acentuada na densidade de plantas (Tabela 2). Houve elevado controle das plantas emergidas após a primeira aplicação do graminicida, observando-se que a densidade de D. horizontalis foi reduzida de 1.071 (Tabela 1) para 103 plantas por metro quadrado (Tabela 2). A tendência continuou sendo de maior número de plantas daninhas no tratamento onde as plantas infestantes foram dessecadas para obtenção de palha; isso é explicado pelo fato de que essas plantas haviam produzido elevada quantidade de sementes por ocasião da dessecação, o que incrementou o banco de sementes. Evidencia-se assim a importância da implantação de culturas de cobertura na redução do banco de sementes, funcionando como estratégia de controle cultural. É importante mencionar que, embora a cobertura do solo com espécies infestantes apresentasse maior número de plantas daninhas, o sistema sem cobertura do solo apresentou maior massa seca das espécies.

Na Tabela 3 são apresentados os dados de massa seca e número de plantas daninhas emergidas por ocasião da colheita da cultura do tomate. A densidade e massa seca de espécies dicotiledôneas continuaram muito

Tabela 2 - Número e massa seca de plantas daninhas emergidas sobre a palha de gramíneas forrageiras na cultura de tomateiro rasteiro conduzido no sistema meia estaca, aos 85 dias após a dessecação, na entrelinha da cultura

\begin{tabular}{|c|c|c|c|c|c|c|c|c|c|c|}
\hline \multirow[b]{2}{*}{ Espécie (plantas $\mathrm{m}^{-2}$ ) } & \multicolumn{10}{|c|}{ Cobertura do solo } \\
\hline & \multicolumn{2}{|c|}{$\begin{array}{l}\text { Brachiaria } \\
\text { decumbens }\end{array}$} & \multicolumn{2}{|c|}{$\begin{array}{l}\text { Brachiaria } \\
\text { ruziziensis }\end{array}$} & \multicolumn{2}{|c|}{$\begin{array}{l}\text { Pennisetum } \\
\text { glaucum }\end{array}$} & \multicolumn{2}{|c|}{ Plantas Daninhas } & \multicolumn{2}{|c|}{ Sem cobertura } \\
\hline Digitaria horizontalis & \multicolumn{2}{|c|}{3} & \multicolumn{2}{|c|}{5} & \multicolumn{2}{|c|}{0} & \multicolumn{2}{|c|}{103} & \multicolumn{2}{|c|}{15} \\
\hline Pennisetum glaucum & \multicolumn{2}{|c|}{0} & \multicolumn{2}{|c|}{0} & \multicolumn{2}{|c|}{37} & \multicolumn{2}{|c|}{0} & \multicolumn{2}{|c|}{0} \\
\hline Eleusine indica & \multicolumn{2}{|c|}{0} & \multicolumn{2}{|c|}{2} & \multicolumn{2}{|c|}{0} & \multicolumn{2}{|c|}{5} & \multicolumn{2}{|c|}{6} \\
\hline Richardia brasiliensis & \multicolumn{2}{|c|}{0} & \multicolumn{2}{|c|}{0} & \multicolumn{2}{|c|}{0} & \multicolumn{2}{|c|}{0} & \multicolumn{2}{|c|}{1} \\
\hline Cyperus rotundus & \multicolumn{2}{|c|}{0} & \multicolumn{2}{|c|}{0} & \multicolumn{2}{|c|}{1} & \multicolumn{2}{|c|}{0} & \multicolumn{2}{|c|}{0} \\
\hline Rebrota $B$. decumbens & \multicolumn{2}{|c|}{4} & \multicolumn{2}{|c|}{0} & \multicolumn{2}{|c|}{0} & \multicolumn{2}{|c|}{0} & \multicolumn{2}{|c|}{0} \\
\hline \multirow{2}{*}{ Massa seca $\left(\mathrm{g} \mathrm{m}^{-2}\right)$} & $\mathrm{M}$ & $\mathrm{D}$ & $\mathrm{M}$ & $\mathrm{D}$ & $\mathrm{M}$ & $\mathrm{D}$ & $\mathrm{M}$ & $\mathrm{D}$ & $\mathrm{M}$ & $\mathrm{D}$ \\
\hline & 3,32 & 0,00 & 0,28 & 0,00 & 0,39 & 0,00 & 8,84 & 0,00 & 10,86 & 0,84 \\
\hline
\end{tabular}

$\mathrm{M}=$ monocotiledôneas; $\mathrm{D}=$ dicotiledôneas . 
Tabela 3 - Número e massa seca de plantas daninhas emergidas sobre a palha de gramíneas forrageiras na cultura de tomateiro rasteiro conduzido no sistema meia estaca, aos 136 dias após a dessecação (final da colheita), na entrelinha da cultura

\begin{tabular}{|c|c|c|c|c|c|c|c|c|c|c|}
\hline \multirow[b]{2}{*}{ Espécie (plantas $\mathrm{m}^{-2}$ ) } & \multicolumn{10}{|c|}{ Cobertura do solo } \\
\hline & \multicolumn{2}{|c|}{$\begin{array}{l}\text { Brachiaria } \\
\text { decumbens }\end{array}$} & \multicolumn{2}{|c|}{$\begin{array}{c}\text { Brachiaria } \\
\text { ruziziensis }\end{array}$} & \multicolumn{2}{|c|}{$\begin{array}{l}\text { Pennisetum } \\
\text { glaucum }\end{array}$} & \multicolumn{2}{|c|}{ Plantas Daninhas } & \multicolumn{2}{|c|}{ Sem cobertura } \\
\hline Digitaria horizontalis & \multicolumn{2}{|c|}{3} & \multicolumn{2}{|c|}{11} & \multicolumn{2}{|c|}{4} & \multicolumn{2}{|c|}{21} & \multicolumn{2}{|c|}{67} \\
\hline Amaranthus sp. & \multicolumn{2}{|c|}{0} & \multicolumn{2}{|c|}{0} & \multicolumn{2}{|c|}{0} & \multicolumn{2}{|c|}{1} & \multicolumn{2}{|c|}{0} \\
\hline Commelina benghalensis & \multicolumn{2}{|c|}{0} & \multicolumn{2}{|c|}{1} & \multicolumn{2}{|c|}{0} & \multicolumn{2}{|c|}{0} & \multicolumn{2}{|c|}{1} \\
\hline Pennisetum glaucum & \multicolumn{2}{|c|}{0} & \multicolumn{2}{|c|}{0} & \multicolumn{2}{|c|}{6} & \multicolumn{2}{|c|}{0} & \multicolumn{2}{|c|}{0} \\
\hline Eleusine indica & \multicolumn{2}{|c|}{0} & \multicolumn{2}{|c|}{3} & & & \multicolumn{2}{|c|}{8} & \multicolumn{2}{|c|}{9} \\
\hline Portulaca oleracea & \multicolumn{2}{|c|}{0} & \multicolumn{2}{|c|}{0} & \multicolumn{2}{|c|}{0} & \multicolumn{2}{|c|}{0} & \multicolumn{2}{|c|}{5} \\
\hline Gnaphalium spicatum & & & & & & & & & & \\
\hline Cyperus rotundus & & & & & & & & & & \\
\hline B. decumbens & & & & & & & & & & \\
\hline Rebrota $B$. decumbens & & & & & & & & & & \\
\hline Rebrota B. ruziziensis & & & & & & & & & & \\
\hline $\mathrm{Ma}$ & $\mathrm{M}$ & $\mathrm{D}$ & $\mathrm{M}$ & $\mathrm{D}$ & $\mathrm{M}$ & $\mathrm{D}$ & $\mathrm{M}$ & $\mathrm{D}$ & $\mathrm{M}$ & $\mathrm{D}$ \\
\hline IVIassa secd (g ill ) & 43,93 & 0,00 & 9,50 & 0,15 & 0,41 & 0,00 & 33,22 & 0,51 & 31,88 & 0,42 \\
\hline
\end{tabular}

$\mathrm{M}=$ monocotiledôneas; $\mathrm{D}=$ dicotiledôneas.

baixas. Observou-se redução na densidade de plantas infestantes gramineas no tratamento com palha de plantas daninhas, o que foi atribuído à competição intraespecífica. Houve aumento da emergência de gramíneas no tratamento sem cobertura do solo, mas em ambos os manejos houve acentuado incremento na massa seca das infestantes, que passou de 8,84 e $10,36 \mathrm{~g} \mathrm{~m}^{-2}$ para 33,22 e $31,88 \mathrm{~g} \mathrm{~m}^{-2}$, respectivamente para os tratamentos com palha de espécies gramíneas e sem palha.

Embora as gramineas forrageiras tenham apresentado excelente controle das plantas infestantes, observou-se rebrota principalmente de $B$. decumbens, a qual representou massa seca superior à das espécies daninhas infestantes no final do ciclo do tomateiro.

As plantas de P. glaucum haviam produzido sementes por ocasião da dessecação; assim, pôde-se observar, nas parcelas onde essa cultura foi semeada, infestação da área com plantas dessa espécie. Todavia, essas plantas foram controladas pelo fluazifop-p-butil. Timossi et al. (2007) também observaram degrana das plantas de $P$. glaucum no fim do ciclo, formando um banco de sementes no solo; contudo, segundo os autores, foi inexpressiva a emergência dessa planta.
Na Tabela 4 encontram-se os dados de plantas infestantes na linha da cultura por ocasião da colheita. A ocorrência de plantas infestantes na linha foi muito baixa. Observou-se maior número de dicotiledôneas, representadas principalmente por Gnaphalium spicatum. Essa espécie, segundo Lorenzi (2000), vegeta na estação de inverno; como a amostragem foi realizada no final do outono, as plântulas da referida espécie começavam a emergir.

Na Tabela 5 é apresentado o resultado da análise estatística da massa seca e densidade total das plantas infestantes, incluindo as rebrotas das forrageiras. Pode-se verificar, aos $46 \mathrm{DAD}$, que não houve diferença significativa entre os tratamentos sem palha e com palha de plantas daninhas, os quais, mesmo após a primeira aplicação dos herbicidas, apresentaram elevada emergência de plantas infestantes, assim como acúmulo de massa seca, diferindo dos tratamentos com cobertura formada por gramíneas forrageiras, que apresentaram densidade e massa seca de plantas daninhas reduzidas. Quanto às demais avaliações, verificou-se que a massa seca no tratamento $\operatorname{com} B$. decumbens não diferiu do solo sem palha e da palha composta por plantas daninhas, o que ocorreu em virtude da rebrota. $P$. glaucum mostrou-se a melhor espécie para 
Tabela 4 - Número e massa seca de plantas daninhas emergidas sobre a palha de gramíneas forrageiras na cultura de tomateiro rasteiro conduzido no sistema meia estaca, aos 136 dias após a dessecação (final da colheita), na linha da cultura

\begin{tabular}{|c|c|c|c|c|c|c|c|c|c|c|}
\hline \multirow{2}{*}{ Espécie (plantas $\mathrm{m}^{-2}$ ) } & \multicolumn{10}{|c|}{ Cobertura do solo } \\
\hline & \multicolumn{2}{|c|}{$\begin{array}{l}\text { Brachiaria } \\
\text { decumbens }\end{array}$} & \multicolumn{2}{|c|}{$\begin{array}{c}\text { Brachiaria } \\
\text { ruziziensis }\end{array}$} & \multicolumn{2}{|c|}{$\begin{array}{l}\text { Pennisetum } \\
\text { glaucum }\end{array}$} & \multicolumn{2}{|c|}{ Plantas Daninhas } & \multicolumn{2}{|c|}{ Sem cobertura } \\
\hline Digitaria horizontalis & \multicolumn{2}{|c|}{1} & \multicolumn{2}{|c|}{2} & \multicolumn{2}{|c|}{2} & \multicolumn{2}{|c|}{0} & \multicolumn{2}{|c|}{7} \\
\hline Amaranthus sp. & \multicolumn{2}{|c|}{0} & \multicolumn{2}{|c|}{2} & \multicolumn{2}{|c|}{1} & \multicolumn{2}{|c|}{1} & \multicolumn{2}{|c|}{0} \\
\hline Commelina benghalensis & \multicolumn{2}{|c|}{0} & \multicolumn{2}{|c|}{0} & \multicolumn{2}{|c|}{1} & \multicolumn{2}{|c|}{1} & \multicolumn{2}{|c|}{0} \\
\hline Eleusine indica & \multicolumn{2}{|c|}{0} & \multicolumn{2}{|c|}{0} & \multicolumn{2}{|c|}{0} & \multicolumn{2}{|c|}{3} & \multicolumn{2}{|c|}{0} \\
\hline Gnaphalium spicatum & \multicolumn{2}{|c|}{3} & \multicolumn{2}{|c|}{4} & \multicolumn{2}{|c|}{3} & \multicolumn{2}{|c|}{2} & \multicolumn{2}{|c|}{0} \\
\hline Cyperus rotundus & \multicolumn{2}{|c|}{0} & \multicolumn{2}{|c|}{1} & \multicolumn{2}{|c|}{0} & \multicolumn{2}{|c|}{0} & \multicolumn{2}{|c|}{1} \\
\hline \multirow{2}{*}{ Massa seca $\left(\mathrm{g} \mathrm{m}^{-2}\right)$} & $\mathrm{M}$ & $\mathrm{D}$ & $\mathrm{M}$ & $\mathrm{D}$ & $\mathrm{M}$ & $\mathrm{D}$ & $\mathrm{M}$ & $\mathrm{D}$ & $\mathrm{M}$ & $\mathrm{D}$ \\
\hline & 0,03 & 0,07 & 0,09 & 0,40 & 0,05 & 0,13 & 0,30 & 0,22 & 0,99 & 0,00 \\
\hline
\end{tabular}

$\mathrm{M}=$ monocotiledôneas; $\mathrm{D}=$ dicotiledôneas.

Tabela 5 - Número e massa seca de plantas daninhas emergidas sobre a palha de gramíneas forrageiras na cultura de tomateiro rasteiro conduzido no sistema meia estaca, aos 46, 85 e 136 dias após a dessecação

\begin{tabular}{|c|c|c|c|c|c|c|}
\hline \multicolumn{7}{|c|}{ Dias após dessecação } \\
\hline \multirow{2}{*}{ Cobertura do solo } & 46 & 85 & 136 & 46 & 85 & 135 \\
\hline & \multicolumn{3}{|c|}{ Massa seca $\left(\mathrm{g} \mathrm{m}^{-2}\right)$} & \multicolumn{3}{|c|}{ Densidade (número $\mathrm{m}^{-2}$ ) } \\
\hline Brachiaria decumbens & $0,96 \mathrm{~B}$ & $3,32 \mathrm{AB}$ & $43,93 \mathrm{~A}$ & $5 \mathrm{~B}$ & $7 \mathrm{~A}$ & $8 \mathrm{~A}$ \\
\hline B. ruziziensis & $0,29 \mathrm{~B}$ & $0,28 \mathrm{~B}$ & $9,65 \mathrm{AB}$ & $25 \mathrm{~B}$ & $7 \mathrm{~A}$ & $16 \mathrm{~A}$ \\
\hline Pennisetum glaucum & $3,26 \mathrm{~B}$ & $0,39 \mathrm{~B}$ & $0,41 \mathrm{~B}$ & $71 \mathrm{~B}$ & $38 \mathrm{~A}$ & $10 \mathrm{~A}$ \\
\hline Plantas Daninhas & $13,36 \mathrm{~A}$ & $8,84 \mathrm{AB}$ & $33,73 \mathrm{AB}$ & $1.212 \mathrm{~A}$ & $108 \mathrm{~A}$ & $31 \mathrm{~A}$ \\
\hline Sem cobertura & $16,83 \mathrm{~A}$ & $11,70 \mathrm{~A}$ & $32,30 \mathrm{AB}$ & $904 \mathrm{~A}$ & $22 \mathrm{~A}$ & $84 \mathrm{~A}$ \\
\hline
\end{tabular}

$\mathrm{M}=$ monocotiledôneas; $\mathrm{D}=$ dicotiledôneas.

controle de plantas daninhas, seguida de $B$. ruziziensis. Não houve diferença significativa na densidade das plantas infestantes após a segunda aplicação dos herbicidas.

O trabalho permitiu concluir que a cobertura do solo com as gramíneas forrageiras para obtenção de palha complementa o controle químico de plantas infestantes na cultura do tomate, conduzido no sistema meia estaca. Todavia, utilizar a comunidade infestante para obtenção de palha promove reduzida cobertura do solo e, juntamente com o tratamento sem cobertura do solo, promove elevada emergência de plantas daninhas.

\section{LITERATURA CITADA}

AMARAL, M. Plantio direto evolui no Brasil. Inf. Agropec., v. 22, n. 208 , p. 3, 2001.
BOER, C. A. et al. Biomassa, decomposição e cobertura do solo ocasionada por resíduos culturais de três espécies vegetais na região Centro-Oeste do Brasil. R. Bras. Ci. Solo, v. 32, n. 2 , p. $843-851,2008$.

CORREIA, N. M.; DURIGAN, J. C.; KLINK, U. P. Influência do tipo e da quantidade de resíduos vegetais na emergência de plantas daninhas. Planta Daninha, v. 24, n. 2 , p. 245-253, 2006.

LORENZI, H. Plantas daninhas do Brasil: terrestres, aquáticas, parasitas e tóxicas. 3.ed. Nova Odessa: Instituto Plantarum, 2000. 608p.

MAROUELLI, W. A.; SILVA, H. R.; MADEIRA, N. R. Uso de água e produção de tomateiro para processamento em sistema de plantio direto com palhada. Pesq. Agropec. Bras., v. 41, n. 9, p. 1399-1404, 2006.

MELO, P. C. T.; VILELA, N. J. Desafios e perspectivas para a cadeia brasileira do tomate para processamento industrial. Hortic. Bras., v. 23, n. 1, p. 154-157, 2005. 
MESCHEDE, D. K.; FERREIRA, A. B.; RIBEIRO JR., C. C Avaliação de diferentes coberturas na supressão de plantas daninhas no Cerrado. Planta Daninha, v. 25, n. 3, p. $465-471,2007$.

NASCENTE, A. S.; PEREIRA, W.; MEDEIROS, M. A. Interferência das plantas daninhas na cultura do tomate para processamento. Hortic. Bras., v. 22, n. 3, p. 602-606, 2004.

PEREIRA, W. Manejo de plantas daninhas em hortaliças Brasília: Embrapa-CNPH, 1987. (Boletim Técnico, 4)

PITELLI, R. A. Interferência de plantas daninhas em culturas olerícolas. In: CONGRESSO BRASILEIRO DE OLERICULTURA, 24.; REUNIÃO LATINO AMERICANA DE OLERICULTURA, 1., 1984, Jaboticabal. Anais... Jaboticabal: FCVAV/Unesp, 1984. p. 75-87.

QASEM, J. R. Pigweed (Amaranthus spp.) interference in transplanted tomato (Lycopersicon esculentum). J. Hortic. Sci., v. 67, n. 3, p. 421-427, 1992.
RODRIGUES, B. N.; ALMEIDA, F. S. Guia de herbicidas. 5.ed. Londrina: 2005. 592 p.

SMEDA, R. J.; WELLER, S. Potential of rye (Secale cereale) for weed management in transplant tomatoes (Lycopersicon esculentum). Weed Sci., v. 44, n. 3, p. $596-602,1996$.

SUZUKI, L. E. A. S.; ALVES, M. C. Fitomassa de plantas de cobertura em diferentes sucessões de culturas e sistemas de cultivo. Bragantia, v. 65, n. 1, p. 121-127, 2006.

TIMOSSI, P. C.; DURIGAN, J. C.; LEITE, G. J. Formação de palhada por braquiárias para adoção do sistema plantio direto. Bragantia, v. 66, n. 4, p. 617-622, 2007.

TREZZI, M. M.; VIDAL, R. A. Potencial de utilização de cobertura vegetal de sorgo e milheto na supressão de plantas daninhas em condição de campo: II - efeitos da cobertura morta. Planta Daninha, v. 22, n. 1, p. 1-10, 2004. 